\title{
Preterm Prelabour Rupture of the Membrane \& Feto-Maternal out come: an Observational Study
}

\author{
S AKTER $^{a}$, R AKTHER $^{b}$, M RASHID $^{a}$
}

Summary:

Objective: The aim of this study was to see the maternal and fetal outcome of preterm pre labor rupture membrane and to identify the risk factors for preterm pre labor rupture membrane.

Methods and Material: This was a cross-sectional descriptive type study carried out in Dhaka Medical College Hospital, Dhaka, during April to September, 2005 (6months) in the Department of Obstetric and Gynecology. 50 pregnant women with preterm premature rupture of the membrane (gestational age 29-0 to 36-6 weeks) were included in this study.

Results: The mean age of the women was 27.24 $16.28 y$ years and $36 \%$ of them more than 30 years old. Sixty two percent women were multi gravid .Socio-economic condition, level of education and antenatal care of the women was low. Median gestational age of the patient was 35weeks. Fifty six percent had previous history of PROM, preterm delivery, abortion, $M R$ and dilatation and curettage. Sixty two percent women had history of sexual activity between 2 to 7 days. Seventy two percent women

Introduction:

Premature rupture of the membrane (PROM) is a common obstetric problem and the assessment of women with possible membrane rupture is a management issue faced in every day practice. When PROM occurs, the fetus loses relative isolation \& protection offered within the amniotic cavity. In general PROM refers to rupture of membranes with leakage of amniotic fluid in the absence of uterine activity. The minimum latency for diagnosis of

a. Dr. Shaida Akter, FCPS, Prof. Maliha Rashid, FCPS, Dhaka Medical Collage Hospital, Dhaka, Bangladesh

b. Dr. Rabeya Akther, FCPS, Bangladesh Bank Medical Center, Dhaka, Bangladesh

Address of Correspondence: Address of Correspondence: Dr. Rabeya Akther Fellow no: 1996(Obstetric \& Gynaecology), Assistant Chief Medical Officer, Bangladesh Bank Medical Center, Motijheel, Dhaka, Bangladesh, Email: rabeyrakther@yahoo.com

Received: 6 November, 200

Accepted: 2 June, 2009 had UTI, anaemia, and lower genital tract infection. Mean duration of the latent period was 18.87 \pm 16.17 hours and time interval of rupture membrane and delivery was $27.60 \pm 21.127$ hours. Eighty four percent patient delivered by vaginal route and Fifty four percent delivered within 24 hours of ruptured membrane. Forty two percent newborn suffered from neonatal asphyxia, respiratory distress syndrome, neonatal jaundice and neonatal sepsis. Thirty two percent women suffered from chorioamnionitis, abruptio placent and endometritis.

Conclusion: PPROM is malnutrition and poverty related disease. Antenatal care is an important tool to prevent PPROM by identifying the risk factors and its management. Steroid for fetal lung maturity, antibiotics to prevent fetal and maternal infection and induction and / or augmentation of labor will speeded delivery and reduce hospital stay and infection.

Key wards: Premature rupture of the membrane, maternal and neonatal outcome, risk factors.

(J Bangladesh Coll Phys Surg 2010; 28: 17-23)

PROM is 1 hour. PROM occurs in approximately $8 \%$ of term pregnancy ${ }^{1}$. Under normal circumstances the fetal membrane ruptures during the active phase of labor. $^{2}$ When PROM occurs before 37 completed weeks, it is called preterm pre labor rupture of the membrane (PPROM). It is responsible for approximately $35 \%$ of all preterm delivery ${ }^{3}$.PROM affects $2.7 \%$ to $17 \%$ of all pregnancies and in most cases happens spontaneously and without apparent cause ${ }^{3}$. PPROM complicates approximately $2 \%-3 \%$ of all pregnancies below 37 weeks gestation ${ }^{1}$. Incidence of preterm PROM in Bangladesh is not known but Incidence of PROM in Dhaka Medical College Hospital is $8.12 \%^{4}$ and $1.94 \%$ at Holy Family Red Crescent Hospital 5. Epidemiological studies have identified several risk factors associated with preterm PROM. Genital tract infection or colonization with various microorganisms, low socioeconomic condition, poor nutrition, anemia, 
poor hygiene, stress, high parity, smoking and ante partum hemorrhage have all been linked to an increased chance of preterm PROM. Education plays a significant role in reducing the risk of PROM especially in developing countries ${ }^{6}$. Preterm premature rupture of the membrane is important for both baby and mother. The survival rate of infants is directly related to their gestational age ${ }^{1}$.There are numerous possible fetal consequences of preterm delivery due to PROM. There are respiratory distress syndrome, hypothermia, hypoglycemia, jaundice, necrotizing enterocolitis, intraventricular hemorrhage, neurologic impairment, apnea, retrolental fibroplasias, bronchopulmpnary dysplasia, patent ductus arteriosus, fetal limb contracture formation, pulmonary hypoplasia and neonatal sepsis depending upon gestational age. PROM causes $20 \%$ of all neonatal death ${ }^{3}$. Probable maternal complications are chorioamnionitis (3-30\%), endometritis, abruptio placenta ${ }^{1,2}$.Recurrence of PROM may occur in $20 \%$ cases. $^{1}$

\section{Aims and Objectives:}

PROM is very common in the obstetric wards. We face problem in diagnosis, monitoring and adopting treatment policy. There were very limited studies about PROM in our country and no national statistics is available about the incidence of PROM or incidence of maternal and perinatal mortality and morbidity from PROM.

The aim of this study is to see the maternal and fetal outcome of preterm premature rupture of the membrane in preterm labor and to identify the risk factors for preterm PROM. It will give an opportunity to analyze the magnitude of problems caused by PROM.

\section{Materials and Methods:}

This is a cross-sectional descriptive type study, done in the Department of Obstetrics and Gynecology in Dhaka Medical College Hospital, Dhaka Bangladesh, from April 2005 to September 2005 (6months). Fifty pregnant women with preterm pre labor rupture of the membrane were recruited from the inpatient of the labor ward of DMCH. Both primi and multi gravid women, who consented to participate in this study, whose pregnancy duration 28 to 36 weeks 6 days ,with spontaneous rupture of the membrane ,not in active labor were included in this study. Women with pregnancy 37 completed weeks, with established labor, with ante partum hemorrhage and with infection were excluded from the study

After admission, full history including duration of pregnancy, time and onset of rupture of membranes, past history of rupture of membranes, past obstetric history was taken. Rupture of the membrane was diagnosed by history of a gush of fluid from the vagina or continued leakage of fluid from the vagina and demonstration of membranes rupture has to be made by a sterile speculum examination visualizing flow of amniotic fluid from the cervical os and / or it's pooling in posterior vaginal fornix spontaneously or by fundal pressure and demonstrating alkaline $\mathrm{P}^{\mathrm{H}}$ of vaginal fluid by litmus paper. During speculum examination high vaginal swab was collected for culture and sensitivity and cervical dilatation and effacement was assessed at the same time. Gestational age was determined from LMP and from early USG scan. Pregnancy of more than 28 weeks duration was included in this study to avoid the conflict of abortion.

Plan of management was decided on gestational age, cervical condition, latent period, presentation of the fetus, symptoms and signs of infection. All patients received a single course of dexamethasone consisting of two $12.5 \mathrm{mg} \mathrm{I} / \mathrm{M}$ injection 12 hourly after admission. Few patients who showed uterine contraction short term tocolysis was given in order to allowed steroid therapy which can produce maximal effect on pulmonary maturation. Fetal surveillance was checked by daily fetal kick count and auscultation of fetal heart sound 4 hourly. All patients received prophylactic antibiotic for 7 days after admission. Inj. Ampicillin / Cephradin 500mg I/V 6 hourly for 48 hours, then this regimen was changed to oral form. This antibiotic was continued for seven days if patient remain undelivered. Maternal monitoring to detect the sign of chorioamnionitis was done by recording of pulse, blood pressure, temperature, fundal height, abdominal tenderness, color and smell of liquor and fetal conditions four hourly. Patients with features of chorioamnionitis which included maternal temperature above $100^{\circ} \mathrm{F}$, maternal tachycardia, fetal tachycardia (fetal heart rate $>160$ beat/minute), uterine tenderness, foul 
smelled vaginal discharge and maternal leucocytosis $(>16000 / \mu \mathrm{L})$ was taken as the indication of termination of pregnancy. Patients with features of chorioamnionitis were given broad spectrum antibiotics in parental route during labor. Antibiotic was given to the baby after delivery in such cases. All the neonates were referred to neonatal ward for further management according to the hospital protocol. Without chorioamnionitis, a conservative approach was taken, advice for bed rest with bathroom facilities, to wear a sterile pad which was inspected every four hourly to detect any change of color of liquor and also to document amount of loss. If patient developed signs and symptoms of infection or conservative approach failed then pregnancy was terminated by induction, augmentation or caesarian section. The labor was induced with misoprostol or augmented with oxytocin drip if there was no contraindication or underwent caesarean section. Data were collected by standard questionnaire from the allocated patients. All data was checked and edited after collection. Then data was entered into computer and analyzed with the help of SPSS win 12software programme.

\section{Results:}

The main objective of the study was to find out the maternal and fetal outcome in preterm premature rupture of the membrane (PPROM) in respect of age, parity, antenatal care, educational background, nutrition, socio-economic condition, and occupation. The findings of the study are presented here.

Table-I shows demographic characteristics of the patients. The mean age of the women was $27.24 \pm 6.278$ years and ranged between 16-40years. Twenty percent belongs to less than 20years age

Table-I

Shows demographic characteristics of the patients

\begin{tabular}{lll}
\hline Variables & & \\
Age of the patients & $27.24 \pm 6.278$ years & \\
& Less than 20years & $12(24 \%)$ \\
Parity & More than 31years & $19(38 \%)$ \\
& Primi & $19(38 \%)$ \\
Income & Multigravid & $41(62 \%)$ \\
& $<4000 /$ taka(monthly) & $20(40 \%)$ \\
Occupation & $4000-8000 / \mathrm{Tk}$ & $25(50 \%)$ \\
& Unemployment & $35(70 \%)$ \\
Education & Service & $15(30 \%)$ \\
& below primary & $16(32 \%)$ \\
Antenatal care & Up to SSC & $18(36 \%)$ \\
& Above SSC & $16(32 \%)$ \\
BMI & Regular & $5(10 \%)$ \\
Gestational age in weeks & Irregular & $20(40 \%)$ \\
Menstrual period & No & $25(50 \%)$ \\
Menstrual cycle & $22.29 \pm 3.48 \mathrm{~kg} / \mathrm{m} 2$ & \\
temperature & $34.74 \pm 2.27 \mathrm{weeks}$ & \\
pulse & $5.40 \pm 1.21 \mathrm{day}$ & \\
SBP & $27.28 \pm 1.43 \mathrm{days}$ & \\
DBP & $98.13 \pm 1.110 \mathrm{~F}$ & \\
Birth weight & $82.62 \pm 11.88 / \mathrm{min}$ & \\
\hline & $128.9 \pm 9.27 \mathrm{mmHg}$ & \\
& $71.2 \pm 8.24 \mathrm{mmHg}$ & \\
& $2.59 \pm .33 \mathrm{~kg}$ & \\
& & \\
& &
\end{tabular}


group and 36\% more than 31 years age group. Mean body mass index is $22.29 \mathrm{~kg} / \mathrm{m}^{2}$. Sixty two percent women were multigravida where as $38 \%$ were primi gravida. Ninty percent women had monthly income $\leq$ $4000-8000 /$ taka. Thirty four (68\%) respondents were educated up to SSC level and remaining 16(32\%) women educated up to degree level.

Sixty two percent (31) patients were house wife and $22 \%$ (11) were service holder. Fifty percent (25) of the patients had no antenatal care and $40 \%$ had irregular and 10\%had regular antenatal care. Mean gestational age of the patient was 34.74 weeks with a standard deviation of \pm 2.266 weeks. Median gestational age of the patient was 35 weeks with a range from $29^{-0}$ to $36^{-6}$ weeks. This table also shown the mean temperature, pulse and blood pressure were $98.13^{0} \mathrm{~F}, 82.62 / \mathrm{min}$ and $128 / 71 \mathrm{mmHg}$ respectively.

Table-II shows distribution of women according to their gestational age. $66 \%$ (33) respondents were near term, 24\% (12) were between 32 to 34 gestational weeks and 5(10\%) were less than 33 weeks.

\section{Table-II}

$\begin{gathered}\text { Shows distribution of respondents according } \\
\text { to their gestational age }\end{gathered}$
\begin{tabular}{lc} 
Gestational age(week) & Frequency \\
\hline $29-0$ to $31+6$ & $5(10 \%)$ \\
$32-0$ to $34+6$ & $12(24 \%)$ \\
$35-0$ to $36+6$ & $33(66 \%)$ \\
\hline Total & $50(100 \%)$
\end{tabular}

Table-III shows, $20 \%$ ( 10) women had previous history of abortion, $14 \%$ (7) had previous history of PROM, $10 \%$ (5) had previous history of preterm delivery due to PROM, $8 \%$ (4) had history of MR and $4 \%$ had history of D\&C.

\section{Table-III}

Shows distribution of obstetric and gynecologic history of the respondents

\begin{tabular}{lc} 
Variables & Frequency \\
\hline History of abortion & $10(20 \%)$ \\
History of PROM & $7(14 \%)$ \\
History of preterm delivery due to PROM & $5(10 \%)$ \\
History of MR & $4(8 \%)$ \\
History of D\&C & $2(4 \%)$ \\
\hline
\end{tabular}

Table-IV shows time of sexual activities before PPROM. $62 \%$ women had history of sexual activities between 2 to 7 days.

\section{Table-IV}

Shows relation of preterm PROM with sexual behavior

\begin{tabular}{lc} 
Time of last coitus & Frequency \\
\hline$<48$ hours & $6(12 \%)$ \\
$2-7$ days & $30(60 \%)$ \\
1 week-1 month & $10(20 \%)$ \\
$>1$ month & $04(08 \%)$ \\
\hline
\end{tabular}

Total 50(100\%)

Table-V shows distribution of associated diseases. $34 \%$ (17) had urinary tract infection, 26\% (13) had anaemia, $12 \%$ (6) had lower genital tract infection, $10 \%$ ( 5) had hypertension, 4\% (2) had diabetes mellitus and $2 \%$ (1) had renal disease.

\section{Table-V}

Shows distribution of associated disease

\begin{tabular}{lc} 
Variables & Frequency \\
\hline Urinary tract infection & $17(34 \%)$ \\
Anaemia & $13(26 \%)$ \\
Lower genital tract infection & $6(12 \%)$ \\
Hypertension & $5(10 \%)$ \\
Diabetes mellitus & $2(4 \%)$ \\
Renal disease & $1(2 \%)$ \\
\hline
\end{tabular}

Table- 6 shows cervical condition at the time of admission. Sixty eight percent women had cervical effacement 0 to $50 \%$ and $32 \%$ had 51 to $100 \%$.Cervical dilatation was less than $2 \mathrm{~cm}$ in $72 \%$ women and more than $2 \mathrm{~cm}$ in $28 \%$ women.

\section{Table-VI}

Shows cervical condition at the time of admission (n-50)

\begin{tabular}{lcc} 
Cervical condition & & Frequency \\
\hline Cervical effacement & $0-51 \%$ & $34(68 \%)$ \\
& $51-100 \%$ & $16(32 \%)$ \\
cervical dilatation & $<2 \mathrm{~cm}$ & $36(72 \%)$ \\
& $>2 \mathrm{~cm}$ & $14(28 \%)$ \\
\hline
\end{tabular}

In this study $78 \%$ women had cephalic, $16 \%$ had breech and $06 \%$ had shoulder presentation.

Table VII shows distribution of latent period. $46 \%$ women start labor pain within 15hours, $26 \%$ women within 16-30hours, $10 \%$ women within $31-45$ hours, 
$8 \%$ women after $45-60$ hours and $10 \%$ women had no labor pain. Mean time interval of rupture membrane and onset of labor pain was 18.87 hours with a standard deviation of \pm 16.19 hours

\section{Table-VII}

Frequency distribution of respondents with gestational age and time interval of membrane rupture to the onset of labor pain $(n=50)$

Time interval of

membrane ruprure

and onset of

\begin{tabular}{|c|c|c|c|c|}
\hline labor pain & \multicolumn{3}{|c|}{ gestational age in weeks } & Total \\
\hline & $29-31$ & $32-34$ & $35-36+$ & \\
\hline $1-15$ hours & 0 & 5 & 18 & 23 \\
\hline 15-30 hours & 0 & 2 & 11 & 13 \\
\hline 31-45 hours & 0 & 1 & 4 & 5 \\
\hline 46-60 hours & 1 & 3 & 0 & 4 \\
\hline No labor pain & 4 & 1 & 0 & 5 \\
\hline Total & $5(10 \%)$ & $12(24 \%)$ & $33(66 \%)$ & $50(100 \%)$ \\
\hline Latent period(mean) & & $18.87 \pm 16$ & 19hours & \\
\hline
\end{tabular}

Table VIII shows time interval between rupture of the membrane and delivery of baby. Twenty four percent

\section{Table-VIII}

Frequency distribution of respondents with gestational age and time interval of membrane rupture to the onset of labor pain $(n=50)$

Time interval of

membrane ruprure

and delivery

\begin{tabular}{cc} 
Parity \\
\hline Primi $\quad$ Multi
\end{tabular}

Total

\begin{tabular}{lccc} 
& Primi & Multi & \\
\hline$<12$ hour & & & \\
& 3 & 9 & $23(46 \%)$ \\
$12-24$ hours & 6 & 9 & $13(26 \%)$
\end{tabular}

24-48hours

$\begin{array}{lccc} & 3 & 8 & 11(22 \%) \\ >48 \text { hours } & 4 & 3 & 7(14 \%) \\ \text { Undelivered } & 3 & 2 & 5(10 \%) \\ & 19(38 \%) & 31(26 \%) & 50(100 \%)\end{array}$

Time interval of $27.60 \pm 21.127$ hours patients with PPROM delivered within 12 hours followed by $15(30 \%)$ patients between $12-24$ hours, $22 \%$ (11) patients between $24-48$ hours, $14 \%$ women after 48 hours and $10 \%$ women remained undelivered. Mean time interval of onset of rupture membrane and delivery was 27.60 hours with a standard deviation of \pm 21.127 hours.

Table IX shows fetal outcome. Average weight of the baby was $2.59 \mathrm{~kg}$. Forty two percent neonates suffers from neonatal asphyxia (2.2\%), respiratory distress syndrome $(11.1 \%)$, neonatal jaundice $(22.2 \%)$ and neonatal sepsis $(6.7 \%)$.

\section{Table-IX}

\begin{tabular}{lc}
\multicolumn{2}{c}{ Fetal outcome } \\
Variables & Percent \\
\hline Neonatal asphyxia & 2.2 \\
Respiratory distress syndrome & 11.1 \\
Neonatal jaundice & 22.2 \\
Neonatal sepsis & 6.7
\end{tabular}

Table X shows maternal outcome. Thirty two percent women suffered from chorioamnionitis (14\%), abruptio placenta (2\%), puerperal sepsis(10\%) ,endometritis(4\%) and wound infection( $2 \%)$.

Table-X

\begin{tabular}{lc}
\multicolumn{2}{c}{ Maternal outcome } \\
Variables & Percent \\
\hline Chorioamnionitis & 14 \\
Endometritis & 4 \\
Puerperal sepsis & 10 \\
Abruptio placenta & 2 \\
Wound infection & 2
\end{tabular}

Figure-1 shows relationship between gestational age and latent period. Onset of labor pain and delivery was earlier in multiparus women than primigravida.

Figure 2 shows association of educational status of respondents and occurrence of UTI. UTI is common among the respondents of lower educational back ground. $X^{2}$ value $=12.517 ; \mathrm{df}=4 ; \mathrm{P}$ value $=0.14$. 


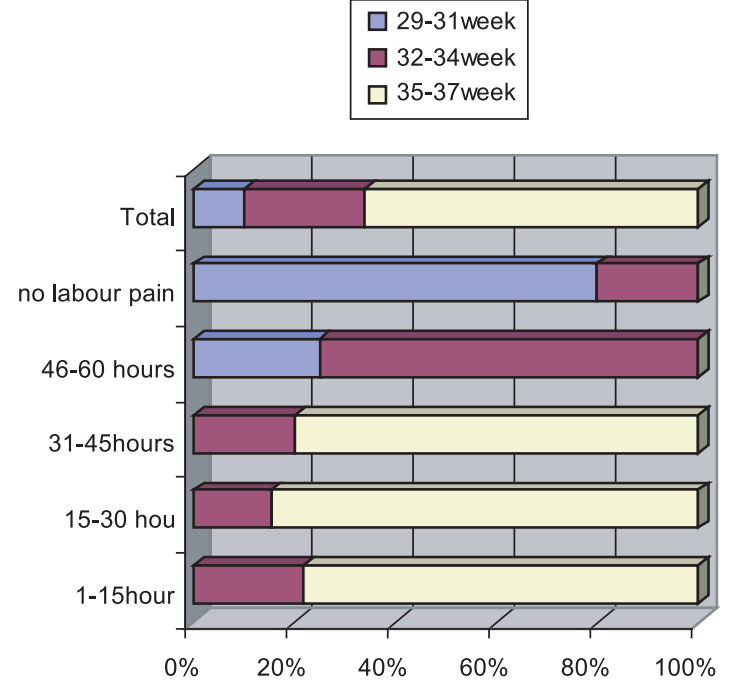

Fig.-1: Relation of gestational age with latent period

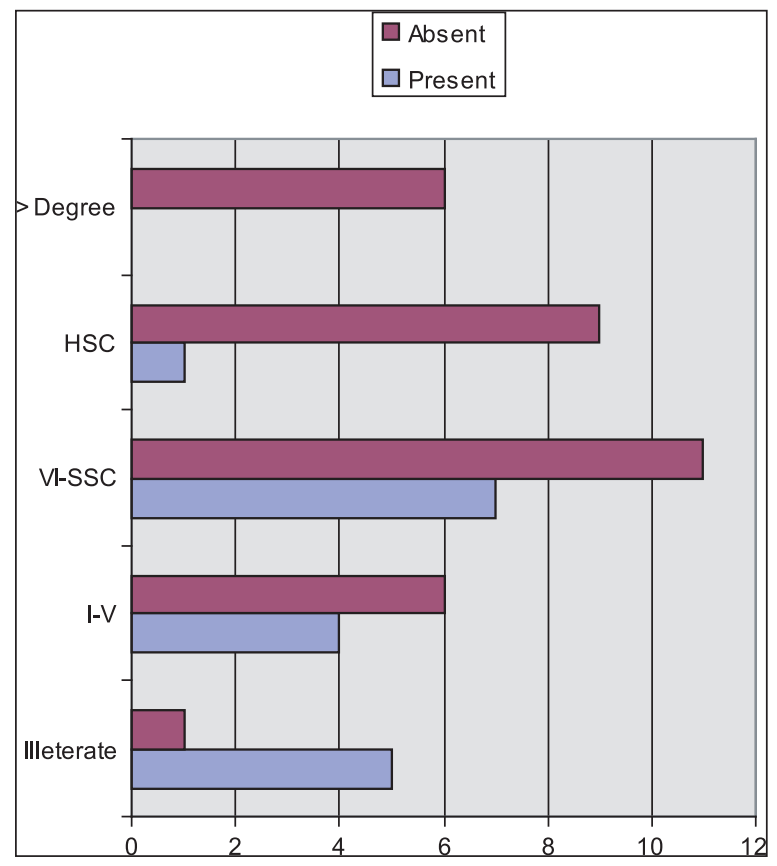

Fig.-2:Association of educational status of respondent and occurrence of $U T I(n-50)$.

\section{Discussion:}

Incidence of PPROM varies from country to country and in the same country, from hospital to hospital. It is due to socioeconomic condition of the patient and also of the country. In $\mathrm{DMCH}$, majority of the women came from lower middle and poor class of the society. PPROM was more common among multiparous ${ }^{7}$ women than primi, this findings is opposite to shaheen et al 5 .Mean age of the patient was $27.24 \pm 6.278$ years, which is similar to other studies $4,7,8$. Previous history of abortion, PROM, preterm delivery due to PROM, menstruation regulation and dilatation and curettage are common among PROM women and in this study $56 \%$ (28) had such type of history 9,10 . In this study, seventy percent patients were housewife and student. It indicates unemployment and its consequence are responsible for PROM. Poverty and illiteracy is interrelated and it affects nutrition, living standard, personal hygiene, immunity and awareness of the patient.

Infection is the most common cause of PPROM and in this study, $34 \%$ had UTI, and $12 \%$ had lower genital tract infection, 1,2,11 .Anaemia, hypertention and diabetes are associated risk factors of PPROM by affecting nutrition and immunity of the patient produce PROM. ${ }^{1,}{ }^{11}$ Subclinical infection, High blood sugar level, over distention of abdomen decrease tensile strength of fetal membrane and vaginal microflora produce mucinase and sialidase enzymes, which facilitate rupture of membrane. ${ }^{12}$

Coitus increases the incidence of PPROM by causing local trauma and also facilitates microbial entrance into the upper genital tract. This study shows that $72 \%$ patients had sexual activity within one week. ${ }^{7}, 10$ but lower rate was observed in other study ${ }^{9}, 5$. Sixty six percent respondents developed PPROM between 35-36 gestational weeks and these findings similar to $\mathrm{S}$. Tasmin ${ }^{4}$ and Shaheen ET $\mathrm{al}^{5}$. Regarding latent period, $46 \%$ women developed labor pain between 115 hours of rupture membrane and another $26 \%$ developed labor pain between 15-30 hours and mean duration of the latent period was 18.87 hours with a std. deviation of \pm 16.186 hours and it has similarity with other studies ${ }^{1,9,10}$. The duration of latency period varies inversely with gestational age. ${ }^{1}$

Regarding mode of delivery, Eighty four percent patient delivered by vaginal route, $15.6 \%$ delivered by caesarean section. Indication of caesarean delivery included the diagnosis of chorioamnionitis, fetal distress and malpresentation.

Mean time interval of rupture membrane and delivery was 27.60 hours with a std. deviation of \pm 21.127 hours. Fifty four percent women delivered within 24 
hours 9,10 and among them $36 \%$ are multi and $18 \%$ are primi. Progress of labor are speeded among women with higher gestational age and gravidity . ${ }^{1}$

Regarding neonatal outcome, we assess neonatal weight which was $2.59 \mathrm{~kg}$. Forty two percent neonates suffered from neonatal asphyxia $(2.2 \%)$, respiratory distress syndrome $(11.1 \%)$, neonatal jaundice $(22.2 \%)$ and neonatal sepsis $(6.7 \%)$ and admitted to special baby care unit. This result is accord with some other studies. ${ }^{4}$ In $\mathrm{DMCH}$, intensive neonatal care facilities are limited .We didn't check fetal lung maturity. Gestational age and birth weight at the time of delivery both affect neonatal survival. More the Gestational age and birth weight, more the rate of surival. $^{2}$

Thirty two percent women suffered from chorioamnionitis $(14 \%)$, abruptio placenta(2\%) ,puerperal sepsis(10\%), endometritis(4\%) and wound infection(2\%). 9,10 Studies shows that bacterial vaginosis group of organism( Gardnerella vaginalis and bacteroid species) and a group of enteropharyngeal organisms were associated with PPROM. ${ }^{12}$. These organisms are normal commensel of vagina. We used ampicillin / cephradin in all cases (hospital supply), while other use erythromycin ${ }^{4}, 13$ and cephradin\& metronidazole ${ }^{5}$. The occurrence of chorioamnionitis (14\%) was more 9, 10. But no chorioamnionitis $^{5}$ among cephradin and metronidazole user. Standard of hospital and management strategy also have some influences on development of chorioamnionitis. We were unable to do C-reactive protein and ultrasonography to predict infection earlier.

\section{Conclusion:}

From the above study, we found that majority of the patients were poor, their access to antenatal care was poor. It might be due to lack of awareness and/ or knowledge. It was presumptive that PPROM was malnutrition and poverty related disease .Antenatal care is an important tool to prevent PPROM by identifying risk factors and its management .Preterm prelabor rupture of membranes has significant impact on perinatal out come. But our main target was healthy mother and healthy baby. In managing PPROM, timely use of proper antibiotics, steroid and induction or augmentation of labor speeded labor, reduce hospital stay and ultimately reduce perinatal and maternal complications.

\section{Reference:}

1. Griff Jones; Pre labour rupture of the membrane; Obstetrics \&Gynaecology-An evidenced based text for MRCOG; Arnold, Member of the hodder headline group.www.arnold publishers.com; 1st edition; Oxford University press; 2004; p297.

2. Andrea CScharfe, Jude P Crino: Pre term labor and Pre labor rupture of the membranes; The Johns Hopkins Manual of Gynecology Obstetrics; 2nd edition, 2000; Lippincot Williams \& Wilkins, USA, p123.

3. Willium's Obstetric Gynaecologic: Pre term labor, Pre labor rupture of the membranes, 19th edition, 1993; Appleton \& Lange, California,USA; p361.

4. Tasnim S, A B Bhuiyan: Outcome of premature rupture of membranes; Bangladesh Journal of Obstetrics\& Gynaecology , 1998;13(1),16-20.

5. Shaheen Rhaman Chowdhury et al; Incidence and outcome of preterm pre mature rupture of membranes and pre term labor at Holy Family Red Crescent Medical College Hospital, Bangladesh Journal of Obstetrics\& Gynaecology , 2005;20(1),19-24

6. Bhide AG: Premature rupture of membranes. In: Krishna U, Tank DK, Daftary S. editors; Pregnancy at risk, Current concepts; 3rd edition; Jaypee Brothers publishers, India; 1997,360 .

7. Begum A, Choudhury: A clinical evaluation of 60 cases; J Inst Postgra Med res 1991; 6:11-15.

8. Moretti M, Sibai BM: Maternal and perinatal outcome of expectant management of premature rupture of membranes in the mid trimester; Am J Obstet Gynecol 1988; 159:390-96.

9. J Sultana,T A Chowdhury, M H Khan,K Begum: Amniotic fluid index values after preterm premature rupture of the membranes and subsequent prenatal infections ; Bangladesh Journal of Obstetrics\& Gynaecology , 2005;20(2),51-55.

10. Ahmed Nazneen. Maternal and fetal outcome in premature rupture of membrane [dissertation] Dhaka Bangladesh College of Physician and Surgeon (BCPS); 2002.

11. Ashley S. Roman,MD,MPH\&Martin L .Pernoll,MD. Late pregnancy complication, Current obstetric Gynaecologic Diagnosis and treatment. 8th edition. Appleton \& Lange. 1994; 286-87.

12. Mcdonald HM, O’Loughlin JA, Jolley P, Vigneswaren R, McDonald PJ; Vaginal infection and preterm labor; Br. J Obstet Gynecol;1991May, 98(5):427-35.

13. kenyon S,Boulvain $\mathrm{M}$, Neilson $\mathrm{J}$ :Antibiotics for preterm pre mature rupture of membranes; ORACLE Clinical Coordinating Centre,Leicester Royal Infirmary, Department of Obstetrics,Clinical Science Building,oracle@le.ac.uk 